\title{
Standardization of building technology on demand via robotic
}

\author{
Andreas Henne ${ }^{1, *}$ and Nina Kloster ${ }^{2}$ \\ ${ }^{1}$ TH Köln, Institut TGA, Betzdorfer Str. 2, 50679 Köln, Deutschland \\ ${ }^{2}$ TH Köln, Institut TGA, Betzdorfer Str. 2, 50679 Köln, Deutschland
}

\begin{abstract}
Although the basic installation arrangement and sequence within Technical Building Equipment, based on generation, distribution and transfer of energy quantities, has remained virtually unchanged for some time, this essentially grid-connected world of installations could soon change significantly for different reasons. This feasibility study presents an almost disruptive approach, based on mobile multifunctional, chargeable and unchargeable PCM-TGA robot technology, which should be able to perform room conditioning (esp. heating, room air quality) as well as room monitoring in at least two rooms via a mobile module. Charging takes place at a plug and play transfer station, e.g. via a decentralized heat pump system integrated in the brickwork. First, the authors show the transdisciplinary reasons, which are essentially socio-politically evidence-based, for the need for additive technological development. Then, both the overall system that consists of a decentralized plug-and-play heat pump transfer station integrated in the brickwork and a mobile robotized heat distribution system, which is not tied to a pipe system, are explained. Based on an exemplary floor plan, living areas will then be shown that require permanent conditioning as well as those that can have discontinuous conditioning via the robot. Feasibility is demonstrated by means of building simulation of the load profiles, leading to appropriate storage dimensioning using a suitable phase change material. Here the authors refer to their extensive theoretical and experimental knowledge in handling dynamic PCMs when creating a prototype. Finally, the technological approach undergoes a critical assessment.
\end{abstract}

\section{Introduction}

The situation in the European and in particular German training system is characterised by a progressing rate of academisation, which has already today led to a shortage of young talent in vocational trades. As a result, many enquiries to plant manufacturers can only be dealt with slowly due to the shortage of personnel, and correspondingly leads to overpricing. In addition, complex building engineering (designated TGA in German) systems, e.g., with regulated primary, secondary and tertiary circuits, are frequently installed nowadays in the mistaken belief that the maximum technically plannable should also be installed and operated $1: 1$. This technological complexity is due to the fact that Germany is poor in primary energy sources. Therefore, Germany is a pioneer in highly energyefficient technology. Moreover, complex and maintenance-intensive plant technology is often used to ensure security of supply. However, who will maintain these systems in the future if there are fewer and fewer qualified personnel?

There is therefore an additive requirement for TGA installations, for the refuge in which human being live $80 \%$ of the time: buildings. The Plug and Play installation presented here with its subsequent robot technology streamlines plant technology. The TGA
Institute of the TH Köln - University of Applied Sciences in Cologne has been conducting research on this topic for quite some time, especially with the focus on the use of phase change materials.

\section{Discontinuous Heating Operation}

In the following, a typical apartment floor plan will be considered, which consists of a living and dining area, bathroom, bedroom (with dressing area), guest room, study, utility room, guest bath, adjoining staircase (with elevator) and a balcony. Living and dining areas as well as bathrooms must be permanently conditioned. However, this does not necessarily apply to the other areas, associated with the omission of technical installations. For example, bedrooms and interior guest baths generally remain completely unheated in modern, energy-efficient buildings, i.e., a temperature control via open doors or adjacent interior masonry is sufficient. In addition, the work area and dressing room should be heated as required. In the further consideration, the aforementioned areas should therefore experience a discontinuous or no heating operation at all. According to Figure 1, for the exemplary $117 \mathrm{~m}^{2}$ apartment (without balcony), $58 \%$ of the area must be heated permanently, $28 \%$ discontinuously and $18 \%$ not at all.

* Corresponding author: andreas.henne@th-koeln.de 


\section{Overall System}

Located in the living and dining area, a heat pump system is integrated into the exterior wall facing the balcony. The evaporator is located on the outside, with an attractive appearance, while the condenser unit is located on the inside. This ends the classic installation! The internal condensing heat transfer station has a double function:

a) Living/dining area as well as the bathroom are 100\% conditioned according to the classic grid-bound installation.

b) A mobile robot system, with integrated PCM heat storage, docks to the transfer station and will be charged by the heat pump. The radiator is able to work at the same time.

The navigable robot supplies the remaining rooms in a discontinuous manner (of course still automated via room thermostats). The heat transfer is comfortable by convection and radiation. An integrated, highly energyefficient intermittent air handling unit (optionally with outside air connection) provides an optional increase in heat output and room air quality will be cleaned of particulate matter /allergens.

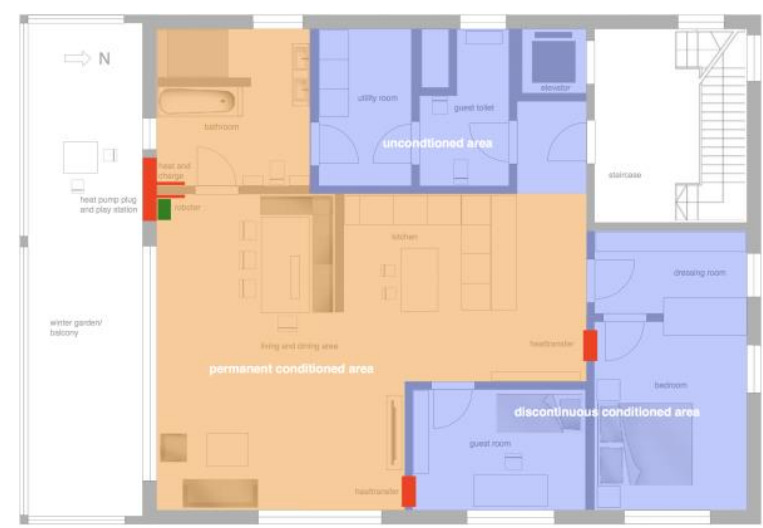

Fig. 1. Overall system with exemplary floor plan

\section{Functional features of the robot}

The robot is charged both thermally and electrically via a docking station, e.g. via the aforementioned heat pump system. The technical building features of the navigable module are subject to the aspects of demand-oriented increase of comfort and health, energy efficiency (use of renewable energy sources), self-sufficiency, operational safety as well as cost and space reduction. The following components are conceivable:

- room air heating (esp. heating function on demand)

- PCM-based energy storage and rechargeable battery

- intermittent air handling system with recuperation

- optional particulate matter filtration of outdoor / circulating air fraction

- room illumination " Lighting on demand "
- detection systems: presence, burglary, fire protection

- operation via smartphone or language

- various

Fields of application : single-family homes, apartment buildings, offices and commercial buildings of generally latest building standards.

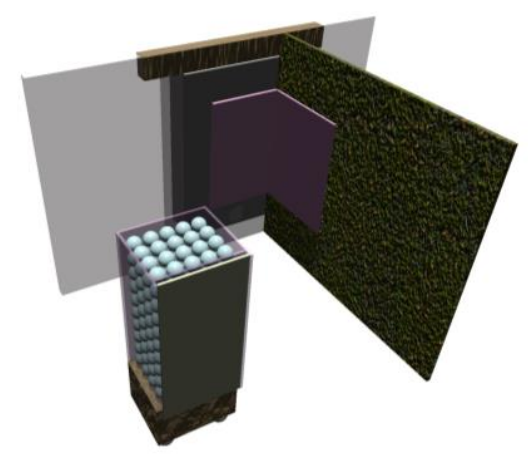

Fig. 2. Charging unit with an exemplary robot geometry

Figure 2 shows an example of how the robot system docks and is loaded onto the condenser of the heat pump integrated in the masonry. The storage tank consists of encapsulated PCM material surrounded by water. The condenser has a double function and conditions the living/dining area on the one hand and the bathroom at the rear on the other. The building technology system is completely wireless.

\section{Feasibility and dimensioning}

The feasibility is shown on the basis of the extensive knowledge of PCMs (1), in an exemplary, realistic heating demand scenario, according of the floor plan shown in Fig. 1, for a site in Cologne.

\subsection{Building simulation}

The subsequent building simulation (TRY) was created by using the simulation tool GBS developed at the TH Köln and validated according to BESTTEST (2). Due to the very good thermal insulation standard (according to EnEV (5) in connection with the controlled ventilation system, the apartment has a heating load of only $2.5 \mathrm{~kW}$ (without controlled ventilation $4.1 \mathrm{~kW}$ ). The hourly heating energy requirement is shown for a cold winter month in Fig. 2 


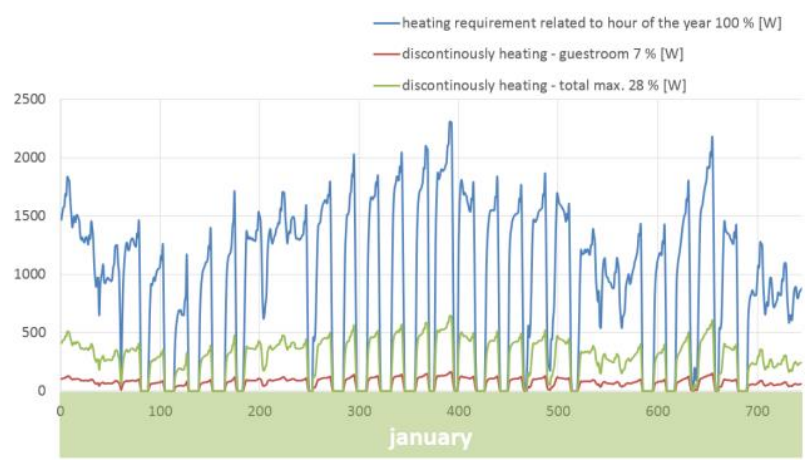

Fig. 3. Simulation of required hourly heating load totally /discontinuously

Simplified, it is now assumed that the hourly, required as already determined - discontinuous heating power is $28 \%$. The peak values for this area are approx. $500 \mathrm{~W}$ for the entire area and, e.g., approx. $200 \mathrm{~W}$ for the guest room/office. However, these values are usually not called up permanently, but normally in sequence. Thus, it is probably irrelevant to cool the bedroom down to $17^{\circ} \mathrm{C}$ during the day. Heating the bedroom could normally take place between $6 \mathrm{pm}$ and $10 \mathrm{pm}$. The mobile system could supply the guest room / study with heat until $6 \mathrm{pm}$. In order to maintain operative temperatures of $20^{\circ} \mathrm{C}$, the rooms would have to be comfort conditioned to $22^{\circ} \mathrm{C}$ air temperature, for example, in order to simultaneously heat the storage mass of the cooled brickwork. It is also assumed that the maximum power requirement for the robot is $300 \mathrm{~W}$, knowing full well that the power could be increased at will via the fan-assisted convection component. However, this would result in faster discharge of the storage tank. A further weather report would then lead to a recharging, e.g. around 8 p.m., due to grid overcapacities caused by wind energy.

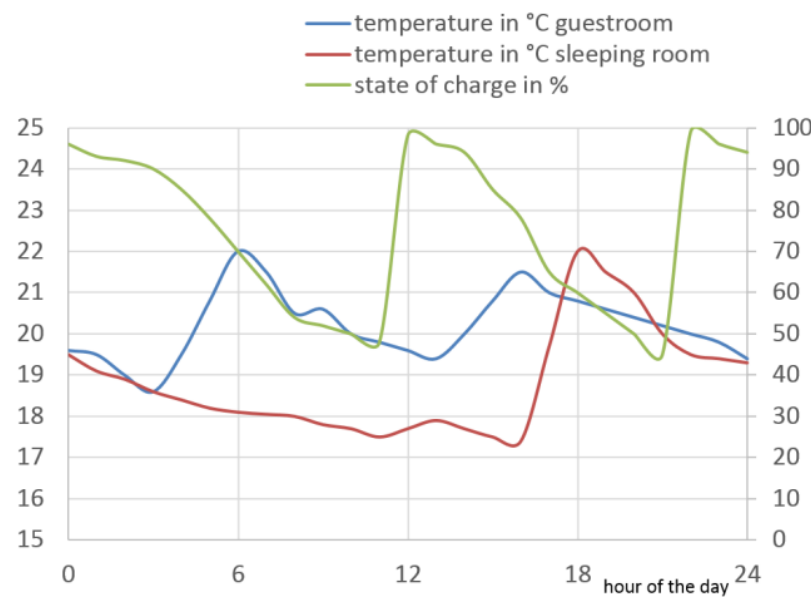

Fig. 4. discontinuous sequential daily course scenario

\subsection{PCM properties}

During the construction of the prototype a phase change material shall be used, which is suitable to heat a room and to be loaded by a heat pump with sufficiently fast dynamics, with an overtemperature of at least $10 \mathrm{~K}$. Therefore, a PCM with a crystallization/melting range of approx. $45^{\circ} \mathrm{C}$ is suitable at maximum flow temperatures in the system of e.g. $55^{\circ} \mathrm{C}$. In order to avoid hypothermia, using paraffin is also specified. Therefore, the PCM RT $44 \mathrm{HC}$ is considered in the following, which corresponds exactly to the above-mentioned properties with a latent heat storage capacity of 250 $\mathrm{kJ} / \mathrm{kg}$. For the calculation of the PCM quantity required in the storage, only the latent effective energy quantity is considered, since the sensitive components are negligible at a specific heat capacity of $2 \mathrm{~kJ} / \mathrm{kg} / \mathrm{K}$, corresponding to the effective temperature differences in the solid and liquid range. This results in the following PCM quantities for a continuous output of $300 \mathrm{~W}$.

A continuous operation of at least $4 \mathrm{~h}$ would be desirable, corresponding to a heat content of $1.2 \mathrm{kWh}$, which would lead to a mass of PCM of approx. $17 \mathrm{~kg}$. In addition, the weight of the construction would probably be the same height, so that the total weight of the system would be approx. $35 \ldots 40 \mathrm{~kg}$.

Table 1. Required PCM quantity

\begin{tabular}{|c|c|c|}
\hline time & energy quantity & quantity of PCM \\
\hline $\mathrm{h}$ & $\mathrm{kWh}$ & $\mathrm{kg}$ \\
\hline 2 & 0,6 & 8,6 \\
\hline 4 & 1,2 & 17,3 \\
\hline 6 & 1,8 & 25,9 \\
\hline
\end{tabular}

\subsection{Storage dynamics}

The requirement portfolio of phase change materials for the purpose of commercial use in TGA plants is considerable; relevant are in particular:

- long-term stability of the PCM

- quantification of the storage state of charge

- dynamics of loading and unloading

- more

The content and stability of many products are now guaranteed by the certification of materials. For years, the Institute of Building Services Engineering at the TH Köln has therefore been focusing its attention on storage dynamics $(3,8)$ and the quantification of the memory charge state within the framework of various investigations. While there are promising approaches to the state of charge, one thing is certain: Storage dynamics can only be achieved by a significant increase in the thermal conductivity in the storage unit, otherwise only insufficient temperature differences occur due to the material inertia. The solution: compounds or metal foam embedded materials $(6,7)$. Another important criterion for charging dynamics is the mentioned overtemperature: the higher, the better. Finally, the installed power of the heat pump is also a criterion. To 
ensure that the $1.2 \mathrm{kWh}$ storage capacity can be quickly recharged, it is recommended that the output be even higher than the max. heating load of $2.5 \mathrm{~kW}$. Future measurements will make this clear. In particular, the focus should be on contact resistance during charging.

\section{Conclusion}

This publication presents an additive heat supply based on a navigable robot with PCM storage. This could become necessary in the future due to a lack of skilled personnel as well as maintenance-intensive, complex plant technology. The system is a technological streamlining that docks to a heat pump based charging station. As with all new approaches, the world of experts is likely to react skeptically with exemplary arguments:

- How will the robot overcome obstacles?

- How is the robot supposed to open a door?

- Where is the thermal comfort?

- What about security of supply?

- How can the system be regulated?

- What about the storage standstill losses?

- How large is the contact charging resistor?

- Where does the electricity come from?

- What does such a system cost?

- and many more

These objections may all be more or less justified, but the authors ask: Since we must have an alternative to the status quo, what should it be?

First of all, we would like to comment on the alleged disadvantages mentioned above. The topic of possible obstacles in the space has already been largely dealt with by companies from the field of robotic vacuum cleaners, which draw their power from charging stations. Obstacles such as doors could be deal with either by automated sliding elements or by heat transfer from the outside, as shown in Figure 1. Heat could even be dissipated simultaneously in two rooms. In any case, the installation effort in the status quo is certainly richer in barriers.

The security of supply, accompanied by thermal comfort, could be compensated for in large apartments by a second robot or an emergency system in the form of an electric air heater, which would certainly not be used too often. Critics could also ask: why not a complete comfort conditioning via air heaters. This would be possible, but is in no way EnEV-compliant according to current legislation (5). All further constructive questions would have to be answered in consistent development work. Once this system is mass-produced, it would be foreseeable that the production costs would be low. Thus, in multi-family homes, for example, there could be identical replacement devices in the basement which could be integrated into the system via WLAN within a very short time. However, the system presented also has many other advantages:

a) The installation effort is reduced to a minimum.

b) In principle, it would be possible to predictively regenerate the storage system from renewable energy sources if the weather is suitable.

c) The system has, since all "losses" remain in the room, according to DIN EN 18599 (4), an energy expenditure factor that moves in the direction of useable energy.

d) The heat could be transferred on demand directly near the user.

e) In combination with an integrated air handling unit with an outside air connection on the basis of intermittent ventilation, roomair of high quality could be generated on site at the user's premises under the following aspects: $\mathrm{O}_{2}$ enrichment, $\mathrm{CO}_{2}$ thinning as well as optional particulate matter filtration if necessary on the basis of HEPA.

f) Further functional features could be integrated, besides LED-based lighting elements, such features would especially include detection systems based on presence, burglary, and fire protection.

g) The operation should preferably be smartphone or speech oriented.

At least continuous heating operation could lead to a reduction of the annual energy consumption. The TGAInstitute of the TH Cologne intends to create a prototype in search of an industrial partner.

\section{References}

1. H. Mehling, Luisa F. Cabeza, Heat and cold storage with PCM: An up to date introduction into basics and applications, Springer Verlag, (2008)

2. ASHRAE standard 140, Standard Method of Test for the Evaluation of Building, 2017

3. J. Goeke, A. Henne, High dynamic thermal heat storage with phase change material, Energy and Power Engineering, (2015)

4. DIN V 18599, Energetische Bewertung von Gebäuden - Berechnung des Nutz-, End- und Primärenergiebedarfs für Heizung, Kühlung, Lüftung, Trinkwarmwasser und Beleuchtung, Beuth Verlag, 2018

5. Bundesministerium der Justiz und für Verbraucherschutz, Verordnung über energiesparenden Wärmeschutz und energiesparende Anlagentechnik bei Gebäuden, 2018

6. C.Y. Zhao, Y. Lu, Y. Tian, Heat transfer enhancement for thermal energy storage using metal foams embedded within phase change materials (PCMs), Solar Energy, Vol.84 (No.8), 2010

7. C.Y. Zhao, T.J. Lu, H.P. Hodson, J.D. Jackson, The temperature dependence of effective thermal conductivity of open-celled steel alloy foams, Materials Science and Engineering A 367, 2004

8. Goeke, J., Popp A., Seasonal thermal storage in buildings, Euroheat \& Power III, 2016 